\title{
Associations of body mass index and gestational weight gain with term pregnancy outcomes in urban Cameroon: a retrospective cohort study in a tertiary hospital
}

Florent Ymele Fouelifack ${ }^{1,2}$, Jeanne Hortence Fouedjio ${ }^{3}$, Jovanny Tsuala Fouogue ${ }^{4^{*}}$, Zacharie Sando ${ }^{5}$, Loic Dongmo Fouelifa ${ }^{6}$ and Robinson Enow $\mathrm{Mbu}^{3}$

\begin{abstract}
Background: Obesity is a rising public health issue worldwide. Guidelines regarding maternal body mass index (BMI) and gestational weight gain (GWG) are missing in Cameroon where maternal mortality rate remains very high. We hypothesized that obesity and inappropriate GWG are associated with poor pregnancy outcomes. We aimed at assessing associations of BMI and GWG with pregnancy outcomes.

Methods: This was a retrospective cohort study at the Yaoundé Central Hospital. We included women with term singleton deliveries in the post-partum ward. The World Health Organisation classification of BMI and the United States Institute Of Medicine (IOM) categories of GWG were used to stratify participants. Poor maternal outcome was defined by the occurence of caesarean section, preeclampsia or obstetrical haemorrhage. Poor perinatal outcome was defined by the occurence of perinatal death, admission in intensive care unit, low birth weight, macrosomia or fifth minute Apgar score $<7$. Multiple logistic regressions were used to calculate unadjusted and adjusted Odds Ratios ( $\mathrm{UOR}$, aOR) for poor maternal outcome (PMO) and for poor perinatal outcome (PPO) in each category of BMI and GWG. Adjustment was done for age, scarred uterus, sickle cell disease, malaria, human immunodeficiency virus (HIV) infection, parity and smoking.
\end{abstract}

Results: Of the 462 participants, 17 (4 \%) were underweight (BMI < 18.5), 228 (49\%) had normal pre-pregnancy BMI, $152(33 \%)$ were overweight $(25 \leq \mathrm{BMl}<30)$ and $65(14 \%)$ were obese $(\mathrm{BMI} \geq 30)$. Following the IOM recommendations, GWG was normal for 186 (40\%) participants, less than recommended for 131 (28\%) and above the recommended norms for 145 (32\%). GWG above the IOM recommendation was significantly associated with PMO (aOR: $1.7,95 \% \mathrm{Cl} 1.1-2.8)$. GWG less than the IOM recommended values, overweight and obesity were not significantly associated with poor pregnancy outcomes.

Conclusion: While waiting for local recommendations for GWG, the IOM recommendations can be used for Cameroonian women as far as maternal outcome is concerned. Unlike in studies in different ethnic and racial groups, abnormal BMI was not associated with poor pregnancy outcomes in our cohort of Cameroonian women.

Keywords: Pregnancy, Body mass index, Outcome, Complications, Obesity, Gestational weight gain, IOM recommendations, Cameroon

\footnotetext{
*Correspondence: fotsujo@outlook.com

${ }^{4}$ Obstetrics and Gynecology unit of the Douala Gynaeco-Obstetric

and Pediatric Hospital, Douala, Cameroon

Full list of author information is available at the end of the article
} 


\section{Background}

Obesity is a rising threat to health worldwide [1]. The trends are the same in Cameroon with marked differences between rural and urban populations on one hand and between men and women on the other hand, the latter being more affected [2-4]. In 2002, the prevalence of obesity among Cameroonian urban women was estimated at $17 \%[3,4]$. It is therefore obvious that the proportion of women entering pregnancy with overweight or obesity will increase. This will constitute a challenge to the health system.

Association between pre-pregnancy obesity and maternal or neonatal morbidity has been demonstrated in developed countries as early as $1945[5,6]$. Several pregnancy complications have been shown to be significantly associated with pre-pregnancy overweight and obesity: miscarriage [7], gestational diabetes [8], induction of labor [8], cesarean section $[8,9]$, post partum hemorrhage [8], preeclampsia [8, 10], dysfunctional labor (slower labor progress from 4 to $10 \mathrm{~cm}$ ) [11], stillbirths [12, 13], neonatal death [13], macrosomia [14] and admission into neonatal intensive care unit [8]. To our knowledge only one study evaluating pregnancy outcomes in Cameroonian obese women has been published [15]. That study found that $64 \%$ of obese women had severe complication [uterine atony (56\%), placenta retention (50\%), placenta accreta (2\%), and cesarean Sect. (21\%)]. The same study reported that $63 \%$ of neonates from obese women had severe complications [macrosomia (11\%), still birth (4\%), poor Apgar score (26\%), intra-partum or early neonatal deaths (13\%)].

Weight gain during pregnancy is attributable to the uterus and its contents (foetus, amniotic fluid and placenta), breasts, blood and interstitial fluid. A smaller fraction of that weight gain is due to an increase in cellular water and deposition of new fat and protein (maternal reserves) $[16,17]$. Though the range of weight gain considered normal is wide, it depends on the pre-gestational body mass index (BMI) [17]. The most widely accepted recommendations for gestational weight gain (GWG) are those issued by the Institute of Medicine (IOM) of the United States of America (Table 1) [18]. There are special populations for which the IOM recommendations are not fully applicable (adolescents, women with multiple foetuses, minority racial and ethnic groups). The rationale behind those guidelines was that pregnancy outcomes are better in women gaining weight within recommended range during pregnancy than in other women. Full implementation of the Institute of Medicine GWG recommendations may reduce obstetric risk, reduce post-partum weight retention, normalize infant birth weight, and improve long-term health [18]. Before undertaking such a public health measure, a pre-requisite
Table 1 The American Institute of Medicine Gestational Weight Gain Recommendations [18]

\begin{tabular}{lll}
\hline $\begin{array}{l}\text { Pre-pregnancy } \\
\text { weight categories }\end{array}$ & $\begin{array}{l}\text { Ranges of body } \\
\text { mass index }\left(\mathbf{k g} / \mathbf{m}^{\mathbf{2}}\right)\end{array}$ & $\begin{array}{l}\text { Recommended total } \\
\text { weight } \mathbf{( k g )}\end{array}$ \\
\hline Underweight & $<18.5$ & $12.5-18$ \\
Normal weight & $18.5-24.9$ & $11.5-16$ \\
Overweight & $25-29.9$ & $7-11.5$ \\
Obese & $\geq 30$ & $5-9$ \\
\hline
\end{tabular}

This table shows the 2009 recommendations of gestational weight gain in each class of body mass index

$\mathrm{kg}$ kilogram, $m^{2}$ square meter

is to assess the validity of the IOM in Cameroonian women. To our knowledge, only two studies have compared outcomes of pregnancies between Cameroonian women who had GWG within the IOM recommended range and those who did not $[19,20]$. The following complications were significantly higher in women with excessive GWG (as per IOM) than in those with recommended GWG: pre-eclampsia, induction of labor, prolonged labor, episiotomy, instrumental delivery, cesarean section, post-partum hemorrhage, acute fetal distress, mal-presentation, macrosomia, birth trauma and poor Apgar score at the first minute (110 overweight women compared to 110 controls) [19]. The second study (231 participants) revealed that the prevalence of macrosomia was significantly higher in case of excessive GWG [20]. Given the scarcity of data on the effects of pre-pregnancy BMI and GWG on pregnancy outcomes in Cameroonian women we carried out this study to fill that knowledge gap. Our objectives were to compare pregnancy outcomes in women with abnormal pre-pregnancy weight to that in women with normal weight (following WHO classification of BMI) and to compare pregnancy outcomes in women with abnormal gestational weight gain to that in women with normal gestational weight gain (following recommendations by the IOM).

\section{Methods}

We carried out a retrospective cohort study at the Yaoundé Central Hospital ( $\mathrm{YCH})$. This is a tertiary and teaching hospital in the capital of Cameroon. We included all women after a singleton term delivery from January 2, 2014 to April 30, 2014. We excluded women with incomplete files, unknown pre-pregnancy weight, severe physical conditions and those who did not consent. Sampling was consecutive.

\section{Measurements of exposure and outcome variables}

We first explained the purpose and the procedure of the study to all women in the post-partum ward. We then invited women to sign the consent form. A confidential 
pretested technical form was used to collect data. Sociodemographic and baseline data were collected on the questionnaire [age, marital status, height, occupation, pre-pregnancy weight (self reported)] and from obstetric records (parity, gestational age at delivery, and weight at the end of pregnancy). Maternal complications were retrieved from obstetric records: hyperemesis gravidarum, malaria, preeclampsia, ante-partum hemorrhage, post-partum hemorrhage, cesarean section, augmentation of labour, gestational age at delivery and non cephalic presentation at birth. Foetal and neonatal complications were retrieved from obstetric records: macrosomia, low birth weight, early neonatal death, intra-uterine death, intra-partum death, acute foetal distress, admission in intensive care unit, Apgar scores at the first and fifth minute. Potential confounders were retrieved from obstetric records: human immunodeficiency virus (HIV) infection, uterine scar, smoking status, malaria in pregnancy and sickle cell disease.

\section{Statistical analysis}

The sample size was calculated with the software Stata ${ }^{\circledR}$ (version 13). The probability on type 1 error was $5 \%$ and the power was $99 \%$. The minimal sample size was 151 , but we included all eligible women during the study period. Microsoft Excel ${ }^{\circledR}$ (version 2010) was used to compile data. We measured association between continuous variables (BMI and GWG) and a binary variable (pregnancy outcome). Adjustment for potential confounders (HIV infection, uterine scar, smoking status, malaria in pregnancy and sickle cell disease) was also done and a multivariable logistic regression was applied. In the first model, independent variable was the pre-pregnancy BMI. In the second model GWG was the independent variable. For both models, we had two categorical outcome variables: poor maternal outcome (PMO) and poor perinatal outcome (PPO). PMO was defined by the presence of at least one of the following complications: cesarean section, preeclampsia and obstetrical haemorrhage. The presence of at least one of the following defined PPO: perinatal death, admission into the intensive care unit, low birth weight (birth weight $<2500$ grams), macrosomia (birth weight $\geq 4000$ grams) and fifth minute Apgar score $<7$. In the first model, PMO and PPO in subgroups with abnormal BMI were compared to the subgroup with normal BMI. In the second model, PMO and PPO in subgroups with abnormal GWG were compared to those in the subgroup with recommended GWG. Unadjusted and adjusted odds ratios ( $\mathrm{uOR}$ and $\mathrm{aOR}$ ) were computed.

\section{Ethical considerations}

Clearance was obtained from the ethical committee of University of Yaoundé 1 . Authorization was obtained from $\mathrm{YCH}$ staff. Written informed consent was compulsory.
Confidentiality was observed. For participants $<16$ year old written informed consent was obtained from a guardian.

\section{Results}

We had 462 participants. The mean age of participants was $27.6 \pm 5.9$ with extremes of 13 and 43 years.

\section{Clinical characteristics and distribution of participants by BMI}

The distribution of participants by clinical characteristics in each class of BMI is described in Table 2.

Seventy-nine per cent of participants were between 20 and 34 year old. HIV prevalence was $7 \%$. Multiparous women accounted for $60 \%$ and women with normal BMI accounted for $49.35 \%$ of participants.

Out of the 462 participants, 17 (4\%) were underweight (BMI < $\left.18.5 \mathrm{~kg} / \mathrm{m}^{2}\right), 228$ (49\%) had normal BMI (18.5 $\leq$ BMI $\leq 24.9)$, 152 (33 \%) were overweight $(25 \leq \mathrm{BMI} \leq 29.9)$ and $65(14 \%)$ were obese (BMI $\geq 30)$. Most of the participants (79\%) were between 20 and 34 years old. Of the 462 participants, 31 (7\%) were smokers, 184 (40\%) were primiparous and 31 (7\%) were HIV infected. Sickle cell disease was found in 11 (3\%) participants and 53 (11\%) had a scarred uterus.

GWG was within IOM 2009 recommendations for 186 (40 \%) participants. GWG was below the IOM 2009 recommendations in 131 (28\%) and above in 145 (32\%) participants.

\section{Clinical characteristics and distribution of participants by GWG}

Table 3 shows the distribution of participants according to clinical characteristics in each category of the IOM 2009 recommendations for GWG. Forty per cent of participants had normal GWG as per IOM. There was no significant difference in the prevalence of clinical characteristics among the different classes of GWG.

\section{Prevalence of maternal and perinatal complications in different classes of BMI}

Table 4 shows distribution of maternal and perinatal complications in different classes of BMI.

The most frequent maternal complication was cesarean section which was found in $38 \%$ of participants. Preeclampsia and obstetrical hemorrhage affected $11 \%$ of participants each. The prevalence of admission in pediatric intensive care unit (ICU) was $13 \%$ while $11 \%$ of our newborns had low birth weight.

\section{Prevalence of maternal and perinatal complications in different categories of GWG}

Rates of maternal and perinatal complications in each class of GWG among participants are detailed in Table 5. 
Table 2 Distribution of participants according to clinical characteristics and BMI

\begin{tabular}{|c|c|c|c|c|c|c|}
\hline \multirow[t]{2}{*}{ Clinical characteristics } & \multicolumn{2}{|c|}{ Prevalence } & \multicolumn{4}{|c|}{ Maternal BMI $\left(\mathrm{kg} / \mathrm{m}^{2}\right)$} \\
\hline & No & $\%$ & $<18.5$ & $18.5-24.9$ & $25.0-29.9$ & $\geq 30.0$ \\
\hline Total & 462 & 100 & 17 & 228 & 152 & 65 \\
\hline \multicolumn{7}{|l|}{ Age (years) } \\
\hline$<20$ & 38 & 8 & 4 & 25 & 8 & 1 \\
\hline $20-34$ & 366 & 79 & 12 & 183 & 122 & 49 \\
\hline$\geq 35$ & 58 & 13 & 1 & 20 & 22 & 15 \\
\hline \multicolumn{7}{|l|}{ Smoking } \\
\hline Yes & 31 & 7 & 1 & 14 & 9 & 7 \\
\hline No & 431 & 93 & 16 & 214 & 143 & 58 \\
\hline \multicolumn{7}{|l|}{ Parity } \\
\hline 0 & 184 & 40 & 8 & 104 & 55 & 17 \\
\hline$\geq 1$ & 278 & 60 & 9 & 124 & 97 & 48 \\
\hline \multicolumn{7}{|l|}{ HIV infection } \\
\hline Yes & 31 & 67 & 0 & 18 & 11 & 2 \\
\hline No & 431 & 93 & 17 & 210 & 141 & 63 \\
\hline \multicolumn{7}{|l|}{ Uterine scar } \\
\hline Yes & 53 & 11 & 0 & 24 & 13 & 16 \\
\hline No & 409 & 89 & 17 & 204 & 139 & 49 \\
\hline \multicolumn{7}{|l|}{ Sickle cell disease } \\
\hline Yes & 11 & 2 & 0 & 6 & 5 & 0 \\
\hline No & 451 & 98 & 17 & 222 & 147 & 65 \\
\hline
\end{tabular}

No absolute number of observations, HIV human immunodeficiency virus

Table 3 Distribution of participants according to clinical socio-characteristics and GWG

\begin{tabular}{|c|c|c|c|c|c|}
\hline \multirow[t]{2}{*}{ Clinical characteristics } & \multicolumn{2}{|c|}{ Prevalence } & \multicolumn{3}{|l|}{ GWG (kg) } \\
\hline & No & $\%$ & GWG < IOM rec. & GWG $=10 M$ rec. & GWG > IOM rec. \\
\hline Total & 462 & 100 & 131 & 186 & 145 \\
\hline \multicolumn{6}{|l|}{ Age (years) } \\
\hline$<20$ & 38 & 8 & 18 & 15 & 5 \\
\hline $20-34$ & 366 & 79 & 103 & 147 & 116 \\
\hline$\geq 35$ & 58 & 13 & 10 & 24 & 24 \\
\hline \multicolumn{6}{|l|}{ Smoking } \\
\hline Yes & 31 & 7 & 2 & 23 & 6 \\
\hline No & 141 & 93 & 129 & 163 & 139 \\
\hline \multicolumn{6}{|l|}{ Parity } \\
\hline 0 & 184 & 40 & 66 & 63 & 55 \\
\hline$\geq 1$ & 278 & 60 & 65 & 123 & 90 \\
\hline \multicolumn{6}{|l|}{ HIV infection } \\
\hline Yes & 31 & 7 & 12 & 13 & 6 \\
\hline No & 431 & 93 & 119 & 173 & 139 \\
\hline \multicolumn{6}{|l|}{ Uterine scar } \\
\hline Yes & 53 & 11 & 12 & 25 & 16 \\
\hline No & 409 & 899 & 119 & 161 & 129 \\
\hline \multicolumn{6}{|l|}{ Sickle cell disease } \\
\hline Yes & 11 & 2 & 2 & 5 & 4 \\
\hline No & 451 & 98 & 129 & 181 & 141 \\
\hline
\end{tabular}

No absolute number of observations, HIV human immunodeficiency virus 
Table 4 Prevalence of maternal and perinatal complications according to BMI

\begin{tabular}{|c|c|c|c|c|c|c|}
\hline \multirow[t]{2}{*}{ Complications } & \multicolumn{2}{|c|}{ Prevalence } & \multicolumn{4}{|c|}{$\mathrm{BMI}\left(\mathrm{kg} / \mathrm{m}^{2}\right)$} \\
\hline & No & $\%$ & $<18.5$ & $18.5-24.9$ & $25.0-29.9$ & $\geq 30.0$ \\
\hline Total & 462 & 100 & $17(\%)$ & $228(\%)$ & $152(\%)$ & $65(\%)$ \\
\hline \multicolumn{7}{|l|}{ Maternal complications } \\
\hline Cesarean section & 176 & 38 & $4(24)$ & $81(36)$ & $63(41)$ & $28(43)$ \\
\hline Obstetrical hemorrhage & 51 & 11 & $1(6)$ & $24(11)$ & $20(13)$ & $6(9)$ \\
\hline Dynamic dystocia & 78 & 17 & $2(12)$ & $44(19)$ & $18(12)$ & $14(22)$ \\
\hline Pre-eclampsia & 51 & 11 & $1(6)$ & $24(11)$ & $20(13)$ & $6(9)$ \\
\hline Poor maternal outcome & 206 & 45 & $4(24)$ & $97(43)$ & $73(48)$ & $32(49)$ \\
\hline \multicolumn{7}{|l|}{ Perinatal complications } \\
\hline Admission ICU & 62 & 13 & $4(24)$ & $33(14)$ & $16(11)$ & $9(14)$ \\
\hline 5th min Apgar score $<7$ & 44 & 910 & $2(12)$ & $21(9)$ & $14(9)$ & $7(11)$ \\
\hline Low birth weight & 51 & 11 & $5(30)$ & $23(10)$ & $17(11)$ & $6(9)$ \\
\hline Macrosomia & 33 & 7 & 0 & $15(7)$ & $12(8)$ & $6(9)$ \\
\hline Perinatal death & 23 & 5 & 0 & $8(4)$ & $9(6)$ & $6(9)$ \\
\hline Poor neonatal outcome & 131 & 28 & $6(35)$ & $62(27)$ & $44(29)$ & $19(29)$ \\
\hline
\end{tabular}

kg kilograms, GWG gestational weight gain, IOM Institute of Medicine, rec. recommendations, ICU intensive care unit

Table 5 Prevalence of specific maternal and perinatal complications and outcomes according to Gestational Weight Gain (GWG)

\begin{tabular}{|c|c|c|c|c|c|}
\hline \multirow[t]{2}{*}{ Complications } & \multicolumn{2}{|c|}{ Prevalence } & \multicolumn{3}{|l|}{ GWG (kg) } \\
\hline & No & $\%$ & GWG < IOM rec. & GWG $=$ IOM rec. & GWG > IOM rec. \\
\hline Total & 462 & 100 & $131(\%)$ & $186(\%)$ & $145(\%)$ \\
\hline \multicolumn{6}{|l|}{ Maternal complications } \\
\hline Cesarean section & 176 & 38 & $34(26)$ & $69(37)$ & $73(50)$ \\
\hline Obstetrical hemorrhage & 51 & 11 & $14(11)$ & $19(10)$ & $18(12)$ \\
\hline Dynamic dystocia & 78 & 17 & $31(24)$ & $30(16)$ & $17(12)$ \\
\hline Pre-eclampsia & 51 & 11 & $14(11)$ & $19(10)$ & $18(12)$ \\
\hline Poor maternal outcome & 206 & 45 & $44(34)$ & $80(43)$ & $82(57)$ \\
\hline \multicolumn{6}{|l|}{ Perinatal complications } \\
\hline Admission ICU & 62 & 13 & $20(15)$ & $26(14)$ & $16(11)$ \\
\hline 5th min Apgar score $<7$ & 44 & 10 & $14(11)$ & $19(10)$ & $11(8)$ \\
\hline Low birth weight & 51 & 11 & $16(12)$ & $25(13)$ & $10(7)$ \\
\hline Macrosomia & 33 & 7 & $6(5)$ & $11(6)$ & $16(11)$ \\
\hline Perinatal death & 23 & 5 & $7(5)$ & $5(3)$ & $11(8)$ \\
\hline Poor perinatal outcome & 131 & 28 & $36(27)$ & $54(29)$ & $41(28)$ \\
\hline
\end{tabular}

kg kilograms, GWG gestational weight gain, IOM Institute of Medicine, rec. recommendations, ICU intensive care unit

The prevalence of PMO was $45 \%$ and that of PPO was $28 \%$. No significant difference was found between rates of complications among different classes of GWG.

\section{Measures of associations between GWG, BMI} and pregnancy outcomes

Unadjusted and adjusted odds ratios expressing associations between GWG and PMO and PPO are shown in Table 6. It also shows associations between BMI and PMO and PPO. BMI was neither associated with PMO nor with PPO. Excessive GWG was associated with PMO (aOR: 1.7; 95 \% CI 1.1-2.8).

\section{Discussion}

Our study found that $4 \%$ (17 out of 462 ) of women were underweight while $14 \%$ (65 out of 462) were obese. Overweight women accounted for $33 \%$ (152 out of 462) of the study population. Pre-pregnancy BMI was normal for $49 \%$ (228 out of 462) of our participants. This distribution is in accordance with a study among pregnant 
Table 6 Associations of BMI and GWG with PMO and PPO

\begin{tabular}{lll}
\hline Exposures and confounders & $\begin{array}{l}\text { PMO } \\
\text { aOR (95 \% Cl) }\end{array}$ & $\begin{array}{l}\text { PPO } \\
\text { aOR (95 \% Cl) }\end{array}$ \\
\hline $\begin{array}{lll}\text { Body mass index } \\
\text { Underweight (BMI < 18.5) }\end{array}$ & $0.5(0.2-1.6)$ & $1.5(0.5-4.3)$ \\
Overweight $(25 \leq \mathrm{BMI} \leq 29.9)$ & $0.8(0.5-1.5)$ & $1.1(0.6-1.9)$ \\
Obesity (BMI $\geq 30)$ & $0.7(0.4-1.3)$ & $0.9(0.5-1.9)$ \\
Normal weight $(18.5 \leq \mathrm{BMI} \leq 25)$ & 1.0 & 1.0 \\
Gestational weight gain & & \\
<Recommended GWG & $0.6(0.4-1.1)$ & $0.9(0.6-1.8)$ \\
$>$ Recommended GWG & $1.7(1.1-2.8)$ & $0.9(0.6-1.6)$ \\
Recommended GWG & 1.0 & 1.0 \\
Age & $1.3(0.78-2.0)$ & $1.2(0.7-1.9)$ \\
Smoking & $0.5(0.8-2.0)$ & $1.1(0.5-2.6)$ \\
Malaria & $1(0.7-1.5)$ & $0.9(0.5-1.3)$ \\
Sickle cell disease & $3.7(0.9-4.8)$ & $1.0(0.3-3.9)$ \\
Uterine scar & $4.9(2.4-9.7)$ & $1.7(0.9-3.3)$ \\
Parity & $0.9(0.6-1.3)$ & $0.9(0.6-1.5)$ \\
HIV infection & $0.3(0.1-0.8)$ & $0.6(0.2-1.5)$ \\
\hline
\end{tabular}

$a O R$ adjusted odds ratio, $V s$ versus, $G W G$ gestational weight gain, $B M I$ body mass index, $P P O$ poor perinatal outcome, $P M O$ poor maternal outcome

Women with GWG above IOM recommendations were at a higher risk (1.7 fold) of having PMO (caesarean section, obstetrical haemorrhage or preeclampsia) are highlighted in italic

women by Mbu et al. and with an anthropometric survey among urban adults by Kamadjeu et al. in Cameroon $[2,19]$. Indeed, they found that $50 \%$ of urban women were either obese or overweight. The proportion of underweight women in our sample $(4 \%)$ was inferior to that reported (7 \%) by Kamadjeu et al. [2]. An explanation is that the prevalence of underweight reported in their study was highest above 55 year old (out of reproductive ages) while $79 \%$ (366 out of 462) of our participants were aged 20-34 year old. Moreover the latest demographic and health survey conducted in Cameroon (2011) revealed that $7 \%$ (1064 out of 15426 ) of women of reproductive age are underweight, the prevalence being highest among those aged 15-19 year old [21]. The same survey reported that the national prevalence of excessive BMI (obesity and overweight) among women of reproductive age in Cameroon was $32 \%$. Figures were higher for educated ( $42 \%$ among the most educated) and wealthy women ( $47 \%$ among the richest stratum) who are more likely to live in urban areas [21]. We had similar findings.

GWG was below the IOM recommendations for 131 (28\%) and above for 145 (31\%) of our participants. These figures appear excessive and raise the question of suitability of the IOM recommendations for our population. Our sample was not representative of the whole population of the country. Participants were recruited in a referral hospital known to have a higher proportion of maternal and foetal complications than the general population. This selection bias added to the fact that even in the USA, almost 1 in 3 women had weight gain outside the IOM recommendations makes that restraint unlikely [17]. The IOM recommendations have been criticized for too narrow limits [22]. A study on sample of 1849 Asian women found that $38 \%$ of pre-pregnancy underweight and $31 \%$ of pre-pregnancy normal BMI women gained less than IOM recommendation [23]. In that study $52 \%$ of overweight women and $64 \%$ of obese women gained more than the recommended weight [23]. A large scale study of 56101 pregnant women in Europe revealed that $74 \%$ of overweight nulliparous women had GWG above the IOM recommendations [24]. Another study in America concluded that out of 5377 women $69 \%$ had GWG out of IOM recommendations [24].

The prevalence of complications was quite high in our sample. The rate of cesarean section was $38 \%$ (176 out of 462). This rate was $26 \%$ among women with GWG below the IOM recommendations, $37 \%$ in those with recommended GWG and $50 \%$ in women with excessive GWG. Similar findings have been reported by Crane et al. [25]. The setting in which the study was conducted is a major referral hospital in the town. This can explain very high rates of cesarean deliveries. Nevertheless, rates of cesarean delivery tend to increase with excessive GWG and to reduce with GWG below the IOM recommendations. Rates of obstetrical hemorrhage (either ante-partum or post-partum hemorrhage) and pre-eclampsia were almost the same in all classes of GWG. This could be explained by the high proportions of primiparous women in each class of GWG (50\% in excessive GWG, $34 \%$ in recommended GWG and 38 \% in GWG below IOM recommendations) in our sample. Indeed it has been proven that primiparous women have a 3.1 relative risk of developing pre-eclampsia [26]. Using that composite, we found that GWG below the IOM recommendations was protective against PMO (uOR: 0.5; $95 \%$ CI 0.4-0.80) but not significantly after adjustment (aOR: 0.6; $95 \% \mathrm{CI}$ 0.4-1.1) the effect size being small. Excessive GWG was significantly associated with PMO (aOR: 1.7; 95 \% CI 1.1-2.8). In previous studies on smaller samples in Cameroon, without adjustment, excessive GWG was significantly associated with pre-eclampsia, cesarean delivery, prolonged labor and postpartum hemorrhage with big effect sizes $[19,20]$. We did adjustment for the following confounders which, taken alone had big effect sizes on maternal outcome: smoking, sickle cell disease, uterine scar, and HIV infection (Table 6). We also adjusted for age, malaria during pregnancy and parity though they had little effect sizes. In a systematic review, the strength of associations of GWG with pre -eclampsia and cesarean delivery has been shown to be dependent upon age, 
parity, race and ethnicity; Researchers were therefore advised to properly address confounders [27].

No significant differences were found between classes of GWG for macrosomia, admission into pediatric intensive care unit (ICU), poor $(<7)$ 5th minute Apgar score, low birth weight and perinatal death. Total rate of admission in paediatric ICU $(13 \%)$ and perinatal deaths $(5 \%)$ found in this study were consistent with the high infant mortality rate that prevails in the country [21]. We observed a low birth weight rate of $11 \%$ which is in line with the national average of $10 \%$ [21]. Though the rate of PPO was high $(28 \%)$ in our study, no association was found with abnormal GWG (Table 6). Some studies found significant association between GWG and adverse perinatal outcomes (macrosomia, low birth weight, large/small-for-gestational age, intra-partum fetal death) but other did not [19, 24, 25, 28]. A systematic review concluded that strong evidence supported association between GWG and macrosomia, low birth weight and large/small-for-gestational age [27].

We found that pre-pregnancy BMI was not significantly associated with pregnancy outcomes (Table 6). This is different from what has been reported by several researchers who worked on larger samples $[6,8,9,10,11$, $12,13,14,29]$. Nonetheless the proportion of PMO was $43 \%$ among women with normal BMI, $48 \%$ among overweight women and $49 \%$ among obese women. This could have been significant in a sample with more participants. Future researches should better explore this issue with larger samples of Cameroonian women.

The main strength of our study is to stand as the first (to our knowledge) to assess pregnancy outcome in all categories of BMI and GWG in Cameroon. Limitations include the following selection bias: our sample was from a cosmopolitan urban area but did not represent all Cameroonian pregnant women. To fully assess the IOM recommendations, a sample representative of all ethnic groups, age, parity, environment and social strata found in the country must be studied. We used hospital-based data of a tertiary center. This hospital is a referral center and therefore has a higher rate of materno-foetal complications than primary health care settings. Rates of pregnancy complications in a population-based study might be more close to their prevalence in the general population. Retrospective collection of data (especially weight) may lead to a certain degree of inaccuracy.

\section{Conclusion}

One-third of women had GWG above the IOM recommendations and there was no difference of proportions following pre-pregnancy BMI. GWG above IOM recommendations was significantly associated with poor maternal outcome but not with poor foetal outcome. No significant association was found between pre-pregnancy BMI and poor materno-foetal outcomes. Prospective population-based cohort studies are needed to further explore association between BMI and GWG with pregnancy outcomes before recommendations are formulated for Cameroonian women.

\begin{abstract}
Abbreviations
aOR: Adjusted odds ratios; BMI: Body mass index; GWG: Gestational weight gain; HIV: Human immunodeficiency virus; ICU: Intensive care unit; IOM: Institute of Medicine; PMO: Poor maternal outcome; PPO: Poor perinatal outcome; u OR: Unadjusted odds ratios; USA: United States of America; YCH:Yaoundé Central Hospital.
\end{abstract}

\section{Authors' contributions}

FYF, JHF, JTF and REM designed the study. JTF, ZS and LDF conducted data collection and analyzed the data. All authors contributed to the drafting and editing of the manuscript as well as the interpretation of the results. All authors read and approved the final manuscript.

\section{Author details}

${ }^{1}$ Obstetrics and Gynecology Unit of Yaoundé Central Hospital, Department of Obstetrics and Gynecology, Higher Institute of Medical Technology of Nkolondom, Yaoundé, Cameroon. ${ }^{2}$ Research, Education and Health Development Group "GARES-Falaise" Dschang-Cameroon, P.O. Box: 31186 , Yaoundé, Cameroon. ${ }^{3}$ Department of Obstetrics and Gynecology of the Faculty of Medicine and Biomedical Sciences of University of Yaoundé 1, Obstetrics and Gynecology Unit of the Yaoundé Central Hospital, Yaoundé, Cameroon. ${ }^{4}$ Obstetrics and Gynecology unit of the Douala Gynaeco-Obstetric and Pediatric Hospital, Douala, Cameroon. ${ }^{5}$ Department of Anatomy and Morphological Sciences of the Faculty of Medicine and Biomedical Sciences of the University of Yaoundé 1, P.O. Box 1364, Yaoundé, Cameroon. ${ }^{6}$ Faculty of Medicine, School of Armies Health Services of Lomé, University of Lomé, P.O. Box: 14148, Lomé, Togo.

\section{Acknowledgements}

We are grateful to all women who accepted to participate in this study. We also express special thanks to teaching staff of the Institute of Tropical Medicine of Antwerp (Belgium) for their constructive critics and for their assistance in statistical analysis.

\section{Competing interests}

The authors declare that they have no competing interests.

Received: 24 January 2015 Accepted: 30 November 2015

Published online: 19 December 2015

\section{References}

1. World Health Organization (WHO). Obesity: preventing and managing the global epidemics. Report of WHO Consultation on Obesity. Geneva: WHO; 1998 (WHO, Geneva, 2006).

2. Kamadjeu RM, Edwards R, Atanga JS, Kiawi CE, Unwin N, Mbanya JC. Anthropometry measures and prevalence of obesity in the urban adult population of Cameroon: an update from the Cameroon Burden of Diabetes Baseline Survey. BMC Public Health. 2006;6:228.

3. Sobngwi E, Mbanya JC, Unwin NC, et al. Physical activity and its relationship with obesity, hypertension and diabetes in urban and rural Cameroon. Int J Obes Relat Metab Disord. 2002;26:1009-16.

4. Abubakari AR, Lauder W, Agyemang C, Jones M, Kirk A, Bhopal RS. Prevalence and time trends in obesity among adult West African populations: a meta-analysis. Obes Rev. 2008;9(4):297-311.

5. Odell LD. The overweight obstetric patient. JAMA. 1945;128:87-90.

6. Galtier-Dereure F, Boegner C, Bringer J. Obesity and pregnancy: complications and cost. Am J Clin Nutr. 2000;71(suppl):1242S-8S.

7. Lashen H, Fear K, Sturdee DW. Obesity is associated with increased risk of first trimester and recurrent miscarriage: matched case-control study. Hum Reprod. 2004;19(7):1644-6. 
8. Sebire NJ, Jolly M, Harris JP, et al. Maternal obesity and pregnancy outcome: a study of 287,213 pregnancies in London. Int J Obes Relat Metab Disord. 2001;25(8):1175-82.

9. Chu SY, Kim SY, Schmid CH, et al. Maternal obesity and risk of cesarean delivery: a meta-analysis. Obes Rev. 2007;8(5):385-94.

10. O'Brien TE, Ray JG, Chan W-S. Maternal body mass index and the risk of preeclampsia: a systematic overview. Epidemiology. 2003;14(3):368-74.

11. Nuthalapaty FS, Rouse DJ, Owen J. The association of maternal weight with cesarean risk, labor duration, and cervical dilation rate during labor induction. Obstet Gynecol. 2004;103(3):452-6 (erratum appears in Obstet Gynecol. 2004;103 (5Pt 1):1019).

12. Chu SY, Kim SY, Lau J, et al. Maternal obesity and risk of stillbirth: a metaanalysis. Am J Obstet Gynecol. 2007;197(3):223-8.

13. Kristensen J, Vestergaard M, Wisborg K, Kesmodel U, Secher NJ. Prepregnancy weight and the risk of stillbirth and neonatal death. BJOG. 2005;112(4):403-8.

14. Cedergren MI. Maternal morbid obesity and the risk of adverse pregnancy outcome. Obstet Gynecol. 2004;103(2):219-24.

15. Nana PN, Wandji JC, Fomulu JN, et al. Materno-foetal outcome of labour in obese women in Yaounde, cameroon. Clin Mother Child Health 2009;6(1):989-93.

16. Royal College of Obstetricians and Gynaecologists. CMACE/RCOG joint guideline: management of women with obesity in pregnancy. London: Royal College of Obstetricians and Gynecologists; 2010

17. American College of Obstetricians and Gynecologists. Obesity in pregnancy. Committee Opinion No. 549. American College of Obstetricians and Gynecologists. Obstet Gynecol. 2013;121:213-7.

18. Davies GA, Maxwell C, McLeod L, et al. SOGC clinical practice guidelines: obesity in pregnancy. No. 239, February 2010. Int J Gynaecol Obstet. 2010;110(2):167-73

19. Galtier-Dereure F, Montpeyroux F, Boulot P, Bringer J, Jaffiol C. Weight excess before pregnancy: complications and cost. Int J Obes Relat Metab Disord. 1995;19:443-8.
20. Ahounkeng NP, Mboudou ET, Adjoby CR, et al. Impact of excessive weight gain during pregnancy on maternal and fetal outcome at the Yaoundé Women's and Children's Hospital (Cameroon). Med Sante Trop. 2014:24(1):63-7.

21. National Institute of Statistics - Cameroon. National Demographic, Health and Multiple Indicators Clusters Survey 2011. Final Report. Yaoundé: National Institute Statistics; 2012. http://www.statistics-cameroon.org.

22. Beyerlein A, Schiessl B, Lack N, von Kries R. Optimal gestational weight gain ranges for the avoidance of adverse birth weight outcomes: a novel approach. Am J Clin Nutr. 2009:90:1552-8.

23. Titapant $V$. Is the US Institute of Medicine recommendation for gestational weight gain suitable for Thai singleton pregnant women? J Med Assoc Thai. 2013;96(1):1-6.

24. Crane JM, White J, Murphy P, Burrage L, Hutchens D. The effect of gestational weight gain by body mass index on maternal and neonatal outcomes. J Obstet Gynaecol Can. 2009;31(1):28-35.

25. Haugen M, Brantsæter AL, Winkvist A, et al. Associations of pre-pregnancy body mass index and gestational weight gain with pregnancy outcome and postpartum weight retention: a prospective observational cohort study. BMC Pregnancy Childbirth. 2014;14:201.

26. Beaufils M, Haddad B, Bavoux F. Hypertension artérielle pendant la grossesse: aspects physiopathologiques et pronostic à long terme. EMC Gynécologie Obstétrique, 5-036-A-10; 2006.

27. Viswanathan M, Siega-Riz AM, Moos MK, et al. Outcomes of maternal weight gain. Evid Rep Technol Assess (Full Rep). 2008;168:1-223.

28. Sunsaneevithayakul P, Titapant $V$, Ruangvutilert $P$, et al. Relation between gestational weight gain and pregnancy outcomes. J Obstet Gynaecol Res. 2014;40(4):995-1001.

29. Sunsaneevithayakul $P$, Titapant $V$, Ruangvutilert $P$, et al. Effect of body mass index on pregnancy outcomes in nulliparous women delivering singleton babies. BMC Public Health. 2007;7:168.

\section{Submit your next manuscript to BioMed Central and we will help you at every step:}

- We accept pre-submission inquiries

- Our selector tool helps you to find the most relevant journal

- We provide round the clock customer support

- Convenient online submission

- Thorough peer review

- Inclusion in PubMed and all major indexing services

- Maximum visibility for your research

Submit your manuscript at www.biomedcentral.com/submit

\section{(O) Biomed Central}

